\title{
Antioxidant and antimicrobial activity of sapodilla (Manilkara zapota L.) fresh, juice and bar
}

\author{
Murnisyazwani, J. and *Rabeta, M.S. \\ Food Technology Division, School of Industrial Technology, Universiti Sains Malaysia, 11800 Minden, \\ Penang, Malaysia
}

\begin{abstract}
Article history:
Received: 14 March 2018

Received in revised form: 2 February 2019

Accepted: 8 February 2019 Available Online: 9 February 2019
\end{abstract}

\section{Keywords:}

Antioxidant,

Antimicrobial,

Sapodilla,

Juice,

Bar

DOI:

https://doi.org/10.26656/fr.2017.3(5).085.A

\begin{abstract}
This study evaluates the antioxidant and antimicrobial activity of sapodilla fresh, juice and bar using three extraction solvents with different polarities (70\% acetone, $80 \%$ ethanol and water). For evaluating antioxidant capacity, Ferric Reducing Antioxidant Power (FRAP) and 1,1-Diphenyl-2-Picrylhydrazyl (DPPH) assays were used. The total flavonoid content (TFC) and condensed tannin of the sapodilla juice and bar extracts were determined as well. Antimicrobial activity was measured using Staphylococcus aureus, Salmonella spp., Escherichia coli and Bacillus subtilis. Both sapodilla bar and juice produced more inhibition of the DPPH assay with $70 \%$ acetone and $80 \%$ ethanol than with the water extraction. The reducing ability of fresh sapodilla was on the order of $70 \%$ acetone $>80 \%$ ethanol $>$ water. The $70 \%$ acetone was the best solvent for yielding condensed tannins. For total flavonoid content, fresh sapodilla and the sapodilla bar and juice showed the highest flavonoid content in $80 \%$ ethanol. The results showed that the $70 \%$ acetone extract for sapodilla bar and juice exhibited stronger antibacterial activity against gram-positive bacteria. Despite some antioxidants being lost in processed food, these still retained important sources of bioactive compounds. Antimicrobial activity done showed different selectivity for sapodilla juice and bar.
\end{abstract}

\section{Introduction}

Sapodilla is an excellent source of antioxidants with over $3000 \mathrm{mg} / \mathrm{L}$ ascorbic acid equivalent antioxidant capacity (AEAC) per $100 \mathrm{~g}$ of fresh sample (Shui et al., 2002). Polyphenols found in immature sapota fruit have been identified as 3'-caffeoylquinic (Lakshminarayana, 1969). Unripe fruits of Manilkara zapota L. contain a high amount of tannin, which may be responsible for the fruit's high antioxidant capacity, although the amount of tannin decreases as it ripens (Lakshminarayana, 1969).

Pathogens, such as Salmonella spp. are a primary cause of food poisoning, and this problem occurs in several parts of the world. Some bacterial strains may cause intestinal infection, which may lead to death (Munazir, 2012). Infectious diseases are a critical problem that is primarily caused by bacteria and fungi from various polluted sources, which may then contaminate food. There is a sudden increase in foodborne illness throughout the world due to the consumption of contaminated food which consists of pathogenic bacteria (Rodriguez et al., 2010). Hence, the effort of finding potential antimicrobial agents is of paramount priority. However, studies also indicated that even new families of antimicrobial agents will have a short life expectancy (Coates et al., 2002). Due to this reason, researchers nowadays are shifting their attention towards the use of natural sources as antimicrobial agents that act against the pathogenic bacteria.

Processing M. zapota L. into fruit products also offers a convenient way to market the fruit, especially because such food products based on sapodilla fruit are not popular in the local market. Fruits processed into value-added products (fruit bars and juice), are not only nutritious but can also be accepted by consumers. Therefore, developing fruit bars and juice from M. zapota L. will increase its commercial value and reduce waste in the production of fruit during any given season. In accordance with these facts, this study was conducted with the aim of identifying the antioxidant activities in M. zapota L. juice and bar which extracted using different type of solvents as well as investigating the antimicrobial activities of $M$. zapota L. against several microorganisms to explore the ability of this fruit as a potential source of natural antimicrobial agent. 


\section{Materials and methods}

\subsection{Sample collection}

Fresh fruits were harvested from Kuala Kurau, Perak Darul Ridzuan $\left(5.0164^{\circ} \mathrm{N}, 100.4318^{\circ} \mathrm{E}\right)$. The herbarium number of M. zapota L. is 11475 .

\subsection{Sample preparation of sapodilla bar}

Sapodilla fruits were weighted, cleaned with tap water, peeled and all the seeds were removed. Then, the fruits were homogenized in a blender (Panasonic MX7995, Malaysia). Approximately $\quad 72.7 \%$ of sapodilla pulps were boiled, and then sugar $(30 \%)$, pectin $(1 \%)$, milk powder $(6 \%)$, citric acid $(0.6 \%)$ and a pinch of salt were added. Then, the homogenized pulp was poured approximately $5-8 \mathrm{~mm}$ thick on the tray that was coated with butter and dried at $60 \pm 2^{\circ} \mathrm{C}$ for $8 \mathrm{hrs}$ in a convection air drier. Finally, the fruit bar was freezedried ((LD53, Kingston, New York).

\subsection{Sapodilla juice}

Both the glass bottle and cap were sterilized in boiling water for 5 mins and then drained and dripped dry. The fruits were cleaned, cut into small pieces and blended in a blender (Panasonic MX-7995, Malaysia). Fruit juice was extracted using a muslin cloth, and the weight of the extracted juice was recorded. An amount of water was weighed to be the same as the weight of extracted juice (1:1 ratio) and added to the extracted juice. The initial soluble solid content in degrees Brix (B1) was measured using a handheld refractometer, and the total weight of the diluted juice (W1) in grams was recorded. The initial titratable acidity of the diluted juice was determined. Each sample was titrated with $0.1 \mathrm{~N}$ of sodium hydroxide $(\mathrm{NaOH})$ to an endpoint $\mathrm{pH}$ of 8.2 . The mixture was warmed to dissolve all the sugars, and the juice was pasteurized at $85^{\circ} \mathrm{C}$ for 3 mins. Then, the caps were closed and filled while hot. Lastly, the juice was blast frozen $\left(-18^{\circ} \mathrm{C}\right)$ prior to freeze-drying and grinding into powder.

\subsection{Sample extraction}

Sample extraction was carried out as described by Ikram et al. (2009) with slight modifications (ratio of sample to solvent). Approximately $1 \mathrm{~g}$ of sample was mixed with $100 \mathrm{~mL}$ of $70 \%$ acetone $(\mathrm{v} / \mathrm{v})$. For the sapodilla bar, the sample was homogenized first using a homogenizer. For sapodilla juice, the sample was ground into powder. Then, the homogenized sapodilla bar and powdered juice samples were placed in a conical flask (wrapped with aluminium foil) and agitated at $150 \mathrm{rpm}\left(27^{\circ} \mathrm{C}\right)$ overnight with the aid of an orbital shaker (Lab Companion, Model SI600R). Then, the mixture was centrifuged at $2500 \mathrm{rpm}$ for $20 \mathrm{mins}$ to obtain a clear solution.

\subsection{Antioxidant analysis}

\subsubsection{DPPH free radical scavenging activity}

Based on the method described by Sanchez-Moreno et al. (1998), the capacity of the extract to scavenge the 2,2-diphenyl-1-picrylhydrazyl (DPPH) radical was measured. Briefly, $2 \mathrm{~mL}$ of the sample extract was added to the $2 \mathrm{~mL}$ of a methanolic solution of DPPH radical $(0.1 \mathrm{mM})$. The mixture was vortexed for $1 \mathrm{~min}$ and maintained in the dark for 30 mins. The absorbance of the mixture was read at a wavelength of $516 \mathrm{~nm}$ against a blank of the methanolic solution of DPPH, which was mixed with distilled water using a UV-vis spectrophotometer, Shimadzu, Japan.

\subsubsection{Ferric reducing antioxidant property (FRAP)}

Ferric reducing antioxidant power (FRAP) reagent was prepared as described by (Benzie and Strain, 1996). A blank sample was prepared by replacing the amount of extract with distilled water. After that, the absorbance was read at $593 \mathrm{~nm}$ using a UV-vis spectrophotometer, Shimadzu, Japan. Ferrous sulphate solution was used as a standard.

\subsection{Determination of total flavonoids content}

The total flavonoid content (TFC) was determined using the aluminium trichloride method as described by $\mathrm{Wu}$ and $\mathrm{Ng}$ (2008). Briefly, $0.5 \mathrm{~mL}$ of sample extract was mixed with $2.5 \mathrm{~mL}$ of distilled water in a test tube followed by the addition of $0.5 \mathrm{~mL}$ of $5 \%(\mathrm{w} / \mathrm{v})$ sodium nitrite solution and maintained for 5 mins. Then, $0.3 \mathrm{~mL}$ of $10 \%(\mathrm{w} / \mathrm{v})$ aluminium chloride was added, and the mixture was incubated for another 6 minutes. After that, $1 \mathrm{~mL}$ of $1 \mathrm{M}$ sodium hydroxide $(10 \%, \mathrm{w} / \mathrm{v})$ was added and immediately make up the solution up to $0.55 \mathrm{~mL}$ with distilled water, vortexed and the absorption of the solution was measured at $510 \mathrm{~nm}$ wavelength by using UV-vis spectrophotometer, Shimadzu, Japan against a reagent blank. A blank sample was prepared by replacing the amount of extract with distilled water. Total flavonoid content was expressed as $\mathrm{mg}$ quercetin equivalent $(\mathrm{QE}) / \mathrm{g}$ of sample.

\subsection{Determination of condensed tannin}

The vanillin- $\mathrm{HCl}$ method described by Broadhurst and Jones (1978) was used to measure tannin. Approximately $0.5 \mathrm{~mL}$ of the sample extract was mixed with the $3 \mathrm{~mL}$ of vanillin reagent $(4 \%, \mathrm{w} / \mathrm{v}$, vanillin in methanol). Then, $1.5 \mathrm{~mL}$ of concentrated hydrochloric acid was added, and the mixture was vortexed. The mixture was maintained in the dark for 15 mins and $27^{\circ} \mathrm{C}$, and the absorbance of the mixture was measured at 
$500 \mathrm{~nm}$ using a UV-vis spectrophotometer, Shimadzu, Japan. A blank sample was prepared using the same procedure without the extract and was used to prepare the calibration curve. Tannins content was expressed as $\mathrm{mg}$ catechin equivalent (CE)/g of sample.

\subsection{Antimicrobial analysis}

\subsubsection{Preparation of culture inoculated for disc diffusion assay}

The disc diffusion method described by the National Committee for Clinical Laboratory Standard (NCCLS) (2015) was used for determination of antimicrobial activity of fresh sapodilla and the sapodilla bar and juice. Each bacterial strain in nutrient agar was transferred into the nutrient broth and incubated approximately 4 to 6 hours before use. After that, the cultures were swabbed on to the Mueller-Hinton agar using a sterilized cotton swab. After that, a petri dish was divided into 5 parts containing 3 types of extraction solvents and positive and negative controls. Sterile blank paper disks were impregnated with $50 \mu \mathrm{L}$ of the sample extracts, dried and placed on the inoculated agar plates. Gentamycin was used as the positive control (Owolabi et al., 2007) while methanol as the negative control in accordance with Sati and Joshi (2011). Plates were incubated at $37^{\circ} \mathrm{C}$ for 18 to $24 \mathrm{~h}$. Antimicrobial activity was determined by measuring the diameter of the clear zones of inhibition.

\subsection{Statistical analysis}

Data were analysed by using SPSS software. Analysis of variance (ANOVA) and Duncan's multiple range method was used to compare any significant differences between solvents. Values were expressed as means \pm standard deviations. Differences were considered significant at $p<0.05$. All the analysis were carried out in triplicates.

\section{Results and discussion}

\subsection{Antioxidant analysis}

\subsubsection{DPPH radical scavenging activity}

Table 1 shows the percentage of DPPH inhibition in sapodilla bar and juice. From the table, the water extract appeared to be lowest for antioxidants in the sapodilla for both products (bar and juice). According to previous studies by Woo et al. (2013), the percentage of DPPH inhibition for sapodilla fruit in $40 \%$ ethanol was $63.20 \pm 0.06 \%$. Since the phytochemical constituents, which are responsible for scavenging free radicals, were higher in the $70 \%$ acetone and $80 \%$ ethanol compared with the water extraction, it can be concluded that higher DPPH radical scavenging activity should be found in combination of water and organic solvents that maximizes the interaction of DPPH radicals with antioxidants present in the sample (Chew et al., 2012). Since amount of total phenolic content could contribute to antioxidant activity in some fruits, prolonged exposure of sapodilla fruit bars to temperature above $60^{\circ} \mathrm{C}$ during drying in a convection oven might have released some of the bound phenolic compounds from the food matrices, resulting in the increased amount of extracted phenols in fruit bars (Dewanto et al., 2002). This significant increase in the total phenolic content might have resulted from the addition of other ingredients and the various reactions that occurred during drying (Rabeta et al., 2016)

Table 1. Percentage of DPPH inhibition in sapodilla bar and juice

\begin{tabular}{cccc}
\hline Sample & $70 \%$ acetone & $70 \%$ ethanol & water \\
\hline Sapodilla Juice & $36.75 \pm 0.89^{\mathrm{a}}$ & $36.75 \pm 1.06^{\mathrm{a}}$ & $14.06 \pm 1.40^{\mathrm{b}}$ \\
Sapodilla Bar & $64.03 \pm 2.12^{\mathrm{a}}$ & $60.08 \pm 5.97^{\mathrm{a}}$ & $40.36 \pm 0.81^{\mathrm{b}}$ \\
\hline
\end{tabular}

Values are means $(\mathrm{n}=3) \pm \mathrm{SD}$. Values with different superscript are significantly different at $p<0.05$

\subsubsection{Ferric reducing antioxidant potential (FRAP)}

Based on the result (Table 2), it can be seen that all the samples for fresh sapodilla juice and bar were significant $(p<0.05)$ in each extract. The reducing ability of fresh sapodilla was on the order of $70 \%$ acetone $>$ $80 \%$ ethanol $>$ water. The $70 \%$ acetone extract had the highest reducing power with $9157.00 \mu \mathrm{M} \mathrm{Fe}(\mathrm{II}) / \mathrm{g}$. The reducing power in $80 \%$ ethanol and water extraction were $8725.33 \mu \mathrm{M} \quad \mathrm{Fe}(\mathrm{II}) / \mathrm{g}$ and $6367 \mu \mathrm{M} \quad \mathrm{Fe}(\mathrm{II}) /$ g, respectively. Addai et al. (2013) reported that the reducing power in the extraction of papaya in $70 \%$ acetone was $7265.17 \mu \mathrm{M}$ TE/g, was $7644.33 \mu \mathrm{M}$ TE/g in $70 \%$ ethanol and was $6391.79 \mu \mathrm{M} \mathrm{TE} / \mathrm{g}$ in water extraction. On the other hand, the $80 \%$ ethanol exhibited a high amount of reducing power with $5880.33 \mu \mathrm{M} \mathrm{Fe}$ (II) $/ g$ in sapodilla bar. The absorbance value measured in the $70 \%$ acetone was $2762.33 \mu \mathrm{M} \quad \mathrm{Fe}(\mathrm{II}) / \mathrm{g}$ and $2570.33 \mu \mathrm{M} \mathrm{Fe}(\mathrm{II}) / \mathrm{g}$ in $80 \%$ ethanol, respectively. The water extract showed the lowest amount of reducing power at $1523.33 \mu \mathrm{M} \mathrm{Fe}(\mathrm{II}) / \mathrm{g}$.

Table 2. FRAP assay in sapodilla bar and juice

\begin{tabular}{cccc}
\hline Sample & $\begin{array}{c}70 \% \\
\text { acetone }\end{array}$ & $\begin{array}{c}70 \% \\
\text { ethanol }\end{array}$ & water \\
\hline \multirow{2}{*}{ Fresh Sapodilla } & $9157.00 \pm$ & $8725.33 \pm$ & $6367.00 \pm$ \\
& $128.33^{\mathrm{a}}$ & $230.76^{\mathrm{b}}$ & $79.73^{\mathrm{c}}$ \\
Sapodilla Bar & $5570.67 \pm$ & $5880.33 \pm$ & $3915.33 \pm$ \\
& $90.84^{\mathrm{b}}$ & $170.54^{\mathrm{a}}$ & $150.89^{\mathrm{c}}$ \\
Sapodilla Juice & $2762.33 \pm$ & $2570.33 \pm$ & $1523.33 \pm$ \\
& $115.85^{\mathrm{a}}$ & $154.08^{\mathrm{b}}$ & $177.68^{\mathrm{c}}$ \\
\hline
\end{tabular}

FRAP assay was expressed as $\mu \mathrm{M} \mathrm{Fe(II)/g.} \mathrm{Values} \mathrm{are} \mathrm{means}$ $(\mathrm{n}=3) \pm \mathrm{SD}$. Values with different superscript are significantly different at $p<0.05$

\subsection{Total flavonoid content}

The results of total flavonoid (Table 3) present in the 
sample, showed significant difference $(p<0.05)$ in the total flavonoid of all sample extracts. The highest content of total flavonoids in fresh sapodilla was obtained from $80 \%$ ethanol extract $(2413.33 \pm 13.5 \mu \mathrm{g}$ QE/g). After $80 \%$ ethanol, $70 \%$ acetone had the highest content of flavonoids $(1735.33 \pm 223.39, \mu \mathrm{g} Q \mathrm{QE} / \mathrm{g})$ and water produced the lowest extraction of flavonoids $(1275.67 \pm 38.94 \mu \mathrm{g} \mathrm{QE} / \mathrm{g})$ in fresh sample. A previous study by Jayakumar and Kanthimathi (2011) demonstrated that $95 \%$ ethanol extract of sapodilla fruit yielded $390 \mu \mathrm{g}$ QE/g. According to Addai et al. (2013), the flavonoid content of papaya in $70 \%$ acetone was $302.4 \pm 0.67 \mu \mathrm{g} \mathrm{QE} / \mathrm{g}$ and was $310.6 \pm 0.54 \mu \mathrm{g} \mathrm{QE} / \mathrm{g}$ in $80 \%$ ethanol and $210.4 \pm 0.63 \mu \mathrm{g} Q E / g$ in water extract. A similar trend was observed in the sapodilla bar, which had the highest flavonoid content in $80 \%$ ethanol (1791.0 $\pm 61.83 \mu \mathrm{g} \mathrm{QE} / \mathrm{g}$ ) followed by $1637.33 \pm 20.03 \mu \mathrm{g}$ $\mathrm{QE} / \mathrm{g}$ in $70 \%$ acetone and water $(1170.33 \pm 2.51 \mu \mathrm{g} \mathrm{QE} /$ g). Among different solvents utilized for the extraction of flavonoids, $80 \%$ ethanol was shown to be the best solvent, and water was observed to be a poor solvent. Acetone was found to be a moderate solvent in the extraction of flavonoids. The interaction of ethanol with flavonoid can be described through non-covalent interactions and provides rapid diffusion into the solution (Castro and Tena, 1996).

Table 3. Total flavonoid content in sapodilla bar and juice

\begin{tabular}{cccc}
\hline Sample & $\begin{array}{c}70 \% \\
\text { acetone }\end{array}$ & $\begin{array}{c}70 \% \\
\text { ethanol }\end{array}$ & water \\
\hline \multirow{2}{*}{ Fresh Sapodilla } & $1735.33 \pm$ & $2413.33 \pm$ & $1275.67 \pm$ \\
& $223.39^{\mathrm{b}}$ & $13.5^{\mathrm{a}}$ & $38.94^{\mathrm{c}}$ \\
Sapodilla Bar & $1637.33 \pm$ & $1791.00 \pm$ & $1170.33 \pm$ \\
& $20.03^{\mathrm{b}}$ & $61.83^{\mathrm{a}}$ & $2.51^{\mathrm{c}}$ \\
Sapodilla Juice & $949.00 \pm 1$ & $1079.00 \pm$ & $945.33 \pm 1$ \\
& $7.08^{\mathrm{b}}$ & $93.66^{\mathrm{a}}$ & $2.85^{\mathrm{b}}$ \\
\hline
\end{tabular}

Total flavonoid content was expressed as $\mu \mathrm{g} \mathrm{QE} / \mathrm{g}$. All data are the mean $\pm \mathrm{SD}$ of three replicates. Values are followed by identical letters are not statistically different from each other $p<0.05$

\subsection{Total condensed tannin}

Tannins not only function as primary antioxidants but secondary plant metabolites and one of the major groups of antioxidant polyphenols that found in food (Kumari et al., 2012). Condensed tannin content of the three samples was determined in this study (Table 4). The highest content of condensed tannins obtained in the $70 \%$ acetone among all of the samples. The $70 \%$ acetone significantly extract more condensed tannins compared to $80 \%$ ethanol and water extraction. Fresh sapodilla extract with $70 \%$ acetone $(2994.67 \pm 21.38 \mu \mathrm{g} \mathrm{CE} / \mathrm{g})$ exhibited the highest condensed tannin, whereas $80 \%$ ethanol $(2694.00 \pm 73.02 \mu \mathrm{g} \mathrm{CE} / \mathrm{g})$ and water extracts produced the lowest amount of condensed tannins $(1738.00 \pm 74.80 \mu \mathrm{g} \mathrm{CE} / \mathrm{g})$. Similar to the sapodilla bar, the $70 \%$ acetone extraction had a proportion of condensed tannin of $1664.00 \pm 112.59 \mu \mathrm{g} \mathrm{CE} / \mathrm{g}$, followed by $70 \%$ ethanol $(1390.00 \pm 13.11 \mu \mathrm{g} \mathrm{CE} / \mathrm{g})$ and water $(868.67 \pm 42.73 \mu \mathrm{g} \mathrm{CE} / \mathrm{g})$. For sapodilla juice, the amount of condensed tannins in $70 \%$ acetone was $1107.33 \pm 84.12 \mu \mathrm{g} \mathrm{CE} / \mathrm{g}$, whereas water exhibited the lowest extraction of condensed tannins $(472.00 \pm 32.19 \mu \mathrm{g} \mathrm{CE} / \mathrm{g})$. Previous studies by Melo et al. (2006) showed that the condensed tannin of banana was $2526 \mu \mathrm{g} \mathrm{CE} / \mathrm{g}$ of fresh weight in an acetone extract. According to Macheix and Fleurite (1990), condensed tannins are not very soluble, and the extraction requires aqueous acetone to break the natural macromolecule linkages of the phenols. The better extraction power of the mixture of alcohol with water indicates that the mixing of a non-polar solvent with water may increase the polarity index of the solvents (Addai et al., 2013).

\begin{tabular}{cccc} 
Table 4. Total condensed tannin in sapodilla bar and juice \\
\cline { 2 - 4 } Sample & $70 \%$ & $70 \%$ & water \\
& acetone & ethanol & \\
\hline \multirow{2}{*}{ Fresh Sapodilla } & $2994.67 \pm$ & $2694.00 \pm$ & $1738.00 \pm$ \\
& $21.38^{\mathrm{a}}$ & $73.02^{\mathrm{b}}$ & $74.80^{\mathrm{c}}$ \\
Sapodilla Bar & $1664.00 \pm$ & $1390.00 \pm$ & $868.67 \pm 4$ \\
& $112.59^{\mathrm{a}}$ & $13.11^{\mathrm{b}}$ & $2.73^{\mathrm{c}}$ \\
Sapodilla Juice & $1107.33 \pm$ & $776.00 \pm 4$. & $472.00 \pm 3$ \\
& $84.12^{\mathrm{a}}$ & $16^{\mathrm{b}}$ & $2.19^{\mathrm{c}}$ \\
\hline
\end{tabular}

Total condensed tannins were expressed as $\mu \mathrm{g} \mathrm{CE} / \mathrm{g}$. Value are means $(n=3) \pm S D$. Values with different superscript are significantly different at $p<0.05$

\subsection{Antimicrobial activity}

The results of the antibacterial activity of the acetone, ethanol and water extracts of all three samples are given in Table 5. The antimicrobial activity of the tested extracts showed different selectivity for each microorganism. The results showed that the $70 \%$ acetone extract for sapodilla bar and juice exhibited stronger antibacterial activity against gram-positive bacteria, whereas their activities towards the gram-negative bacteria was found to be weak. The gram-positive bacteria seemed to be more easily inhibited than gramnegative bacteria. For sapodilla bar, the highest zone of inhibition was $12.7 \mathrm{~mm}$ against $B$. subtilis (extracted with $70 \%$ acetone).

Sapodilla juice with $70 \%$ acetone exhibited greater antimicrobial effect towards B. subtilis at $9.3 \mathrm{~mm}$ as compared to other extraction solvent. Both samples showed weak inhibition against Salmonella spp. at 5.0 $\mathrm{mm}$ for sapodilla bar and $3.0 \mathrm{~mm}$ for sapodilla juice (extracted with $70 \%$ acetone). Salmonella spp. was found to be most susceptible to the fresh sapodilla extract with an inhibition zone $2.0 \mathrm{~mm}$. The $80 \%$ ethanol extracts of the sapodilla bar showed weak inhibition against $E$. coli $(1.0 \mathrm{~mm})$, and a larger inhibition zone was 
Table 5. Antimicrobial activity of fresh sapodilla, sapodilla bar and juice

\begin{tabular}{lcccccccccc}
\hline & \multicolumn{10}{c}{ Zone of Inhibition (mm) } \\
\cline { 2 - 10 } Microorganisms & \multicolumn{9}{c}{ Fresh Sapodilla } & \multicolumn{3}{c}{ Sapodila Bar } & \multicolumn{3}{c}{ Sapodila Juice } & Antimicrobial Disc \\
\cline { 2 - 10 } & Acetone Ethanol & Water & Acetone Ethanol & Water & Acetone Ethanol & Water & Gentamycin \\
\hline E. coli & 5.0 & - & - & 7.3 & 1.0 & - & 7.0 & 3.0 & - & 16.0 \\
Salmonella spp. & 2.0 & - & - & 5.0 & 2.0 & - & 3.0 & 2.0 & 4.0 & 19.0 \\
B. subtilis & 7.3 & 5.0 & 3.3 & 12.7 & 8.3 & 7.3 & 9.3 & 9.0 & 6.5 & 22.0 \\
S. aureus & 8.0 & 8.0 & 5.0 & 9.0 & 10.0 & 7.0 & 10.0 & 8.7 & 7.0 & 20.0 \\
\hline
\end{tabular}

- no inhibition zone

found against $S$. aureus $(10.0 \mathrm{~mm})$. In $80 \%$ ethanol extract, fresh sapodilla was inactive against $E$. coli and Salmonella spp. but showed a minor inhibition effect against $B$. subtilis $(5.0 \mathrm{~mm})$ and $S$. aureus $(8.0$ $\mathrm{mm}$ ) while the sapodilla juice extract was quite effective against $B$. subtilis $(9.0 \mathrm{~mm})$ and $S$. aureus $(8.7 \mathrm{~mm})$.

It is worth noting that all the extracts showed greater antibacterial activity against gram-positive bacteria than gram-negative bacteria. All the extracts showed activity against $B$. subtilis and $S$. aureus, which are generally more sensitive to the sample extracts. The reason for this difference in sensitivity towards the plant extracts might be due to the difference in the morphological constitution of these microorganisms. According to Chaghaby (2014), gram-negative bacteria have an outer phospholipidic membrane consisting of lipoprotein and lipopolysaccharide that makes the cell wall impermeable to plant extracts. This membrane renders the gramnegative bacteria generally less susceptible to plant extracts than the gram-positive bacteria (Chan et al., 2012). On the other hand, gram-positive bacteria are more susceptible and only have an outer peptidoglycan layer that is not an effective permeability barrier (Chanda et al., 2010). The antibacterial activity of the extracts might be due to the presence of bioactive compounds such as tannins, flavonoids and phenolic acid (Ouattara et al., 2011). Fresh sapodilla extracts have the lowest inhibition against both gram-positive and gram-negative bacteria. No results have been published on the antimicrobial activity of $M$. zapota L., but studies from (Patel and Rao, 2012), who screened the antibacterial activity of Manilkara hexandra, showed that acetone extracts exhibited the lowest antibacterial activity in ripe fruit. Based on the results, the $B$. subtilis inhibition zone is only $2.0 \mathrm{~mm}$, whereas $E$. coli exhibited a $3.0 \mathrm{~mm}$ inhibition zone. Previous study found that the formulated juice had better microbial stability (Lim et al., 2018).

\section{Conclusion}

Although some antioxidant losses could have occurred, the present results suggest that fruit bar and juice may still represent important sources of bioactive compounds in the diet with noticeable antioxidant capacity. Sapodilla bar and juice have higher antimicrobial activities compared to fresh sapodilla. However, the results of flavonoid content and condensed tannins in the sapodilla bar and juice in this study were lower than fresh sapodilla. The results should indicate a higher inhibition zone in fresh sapodilla. This result might be due to the effect of the addition of sugar to sapodilla bar and juice, which acts as a preservative. Greater inhibition in the samples might be due to the presence of the solvent used. The overall study has demonstrated the potentiality of sapodilla fruit bar and juice as cheap resources of natural microbial agents against pathogenic microorganisms which may overcome the current problem of expensive medical cost in the societies.

\section{Conflict of Interest}

We declare that we have no conflict of interest.

\section{Acknowledgments}

Short term grant of Universiti Sains Malaysia (304/ PTEKIND/6312124) contributed to the funding of this research.

\section{References}

Addai, A.R., Abdullah, A. and Mutalib, S.A. (2013). Effect of extraction solvents on the phenolic content and antioxidant properties of two papaya cultivars. Journal of Medicinal Plants Research, 7(47), 33543359.

Benzie, I.F.F. and Strain, J.J. (1996). The ferric reducing ability of plasma (FRAP) as a measure of "Antioxidant Power": The Frap Assay. Analytical Biochemistry, 239(1), 70-76. https://doi.org/10.1006/ abio. 1996.0292

Castro, M.D and Tena, M.T. (1996). Strategies for supercritical fluid extraction of polar and ionic compounds. Trends in Analytical Chemistry, 15(1), 32-38. https://doi.org/10.1016/0165-9936(96)880356

Chaghaby, G.A.E., Ahamd, A.F. and Ramis, S. (2014). Evaluation of the antioxidant and antibacterial properties of various solvents extracts of Annona squamosa L. leaves. Arabian Journal of Chemistry, 
$7(2), \quad 227-233 . \quad$ https://doi.org/10.1016/ j.arabjc.2011.06.019

Chan, E.W.C., Kong, L.Q, Yee, K.Y., Chua, W.Y. and Loo T.Y. (2012). Rosemary and sage outperformed six other culinary herbs in antioxidant and antibacterial properties. International Journal of Biotechnology for Wellness Industries, 1(2), 142$151 . \quad$ https://doi.org/10.6000/1927$3037 / 2012.01 .02 .06$

Chanda, S., Dudhatra, S. and Kaneria, M. (2010). Antioxidative and antibacterial effects of seeds and fruit rind of nutraceutical plants belonging to the Fabaceae family. Food Function, 1(3), 308-315. https://doi.org/10.1039/c0fo00028k

Chew, L.Y, Khoo, H.E, Amin, I., Azrina, A. and Lau, C.Y. (2012). Analysis of phenolic compounds of Dabai (Canarium odontophyllum Miq.) fruits by high-performance liquid chromatography. Food Analysis Methods, 5(1), 126-137. https:// doi.org/10.1039/c0fo00028k

Coates, A., Hu, Y., Bax, R. and Page, C. (2002). The future challenges facing the development of new antimicrobial drugs. Nature Reviews Drug Discovery, 1, 895-910. https://doi.org/10.1038/ $\operatorname{nrd} 940$

Dewanto, V., Wu, X.Z., Adom, K.K. and Liu R.H. (2002). Thermal processing enhances the nutritional value of tomatoes by increasing total antioxidant activity. Journal of Agricultural and Food Chemistry, 50(10), 3010-3014. https:// doi.org/10.1021/jf0115589

Ikram, E.H.K, Eng, K.H, Jalil, A.M.M., Ismail, A., Idris, S., Azlan, A., Nazri, H.S.M., Diton, N.A.M. and Mokhtar, R.A.M. (2009). Antioxidant capacity and total phenolic content of Malaysian underutilized fruits. Journal of Food Composition and Analysis, 22 (5), 388-393. https://doi.org/10.1016/ j.jfca.2009.04.001

Jayakumar, M. and Kanthimathi, M.S. (2011). Inhibitory effects of fruit extracts on nitric oxide-induced proliferation in MCF-7 cells. Food Chemistry, 126 (3), 956-960. https://doi.org/10.1016/ j.foodchem.2010.11.093

Kumari, M. and Jain, S. (2012). Tannins: An antinutrient with positive effect to manage diabetes. Research Journal of Recent Sciences, 1(12), 70-73.

Lakshminarayana, S., Mathew, A.G. and Parpia, H.A.B. (1969). Changes in polyphenols of sapota fruit (Achras zapota L.) during maturation. Journal Sciences Food Agriculture, 20(11), 651-653. https:// doi.org/10.1002/jsfa.2740201105

Lim, W.S., Rabeta, M.S. and Uthumporn, U. (2018).
Development of functional beverage from Sapodilla (Manilkara zapota L.) fruit. Food Research, 2(2), 163 - 170. https://doi.org/10.26656/fr.2017.2(2).227

Macheix, J.J. and Fleurite, A. (1990). 'Fruit phenolics', Phenolic Compounds in Fruit Processing, p. 323. Florida: Boca Raton

Melo, E.A., Lima, V.L.A.G. and Maciel, M.I.S. (2006). Polyphenol, ascorbic acid and total carotenoid contents in common fruits and vegetables. Brazilian Journal of Food Technology, 9(2), 89-94.

Munazir, M., Qureshi, R., Arshad, M. and Gulfaraz, M. (2012). Antibacterial activity of root and fruit extracts of Leptadenia pyrotechnica (Asclepiadaceae) from Pakistan. Pakistan Journal Botany, 44(4), 1209-1213.

National Committee for Clinical Laboratory Standard (NCCLS). 2015. M100 Performance Standards for Antimicrobial Susceptibility Testing. Retrieved from NCCLS website: http://clsi.org/

Ouattara, L., Koudou, J., Zongo, C., Barro, N., Savadogo, A., Bassole, I.H.N., Ouattara, A.S. and Traore, A.S. (2011). Antioxidant and antibacterial activities of three species of Lannea from Burkina Faso. Journal of Applied Sciences, 11(1), 157-162. https://doi.org/10.3923/jas.2011.157.162

Owolabi, O.J., Omogbai, E.K.I. and Obasuyi, O. (2007). Antifungal and antibacterial activities of the ethanolic and aqueous extract of Kigelia Africana (Bignoniaceae) stem bark. African Journal of Biotechnology, 6(14), 1677-1680.

Patel, P.R. and Rao, T.V.R. (2012). Screening of antibacterial activity of some underutilized fruits of Sapotaceae. International Food Research Journal, 19(3), 1227-1231.

Rabeta, M.S., Tee, L.Y. and Leila, M. (2016). Development of Fruit Bar Using Sapodilla (Manilkara zapota L.). Journal of Food Processing and Preservation, 41(2), 1-7.

Rodriguez, V., Maria, J., Pedro, A.F., Maria, M.N. and Saad, A.M. (2010). Phenolic compound combinations on Escherichia coli viability in a meat system. Journal of Agriculture and Food Chemistry, 58(10), 6048-6052. https://doi.org/10.1021/ jf903966p

Sanchez-Moreno, C., Larrauri, J.A. and Saura-Calixto, F. (1998). A procedure to measure the anti-radical efficiency of polyphenols. Journal of the Science of Food and Agriculture, 76, 270-276. https:// doi.org/10.1002/(SICI)1097-0010(199802)

76:2<270::AID-JSFA945>3.0.CO;2-9

Sati, S.C. and Joshi, S. (2011). Antibacterial activity of the Himalayan lichen Parmotrema nilgherrense 
extracts. British Microbiology Research Journal, 1 (2), 26-32. https://doi.org/10.9734/BMRJ/2011/211

Shui, G. and Leong, L. (2002). An investigation of antioxidant capacity of fruits in Singapore markets. Food Chemistry, 76(1), 69-75. https:// doi.org/10.1016/S0308-8146(01)00251-5

Woo, P.F., Yim, H.S., Khoo, H.E., Sia, C.M. and Ang, Y.K. (2013). Effects of extraction conditions on antioxidant properties of sapodilla fruit (Manilkara zapota). International Food Research Journal, 20 (5), 2065-2072.

$\mathrm{Wu}$, S.J, and $\mathrm{Ng}$, L.T. (2008). Antioxidant and free radical scavenging activities of wild bitter melon (Momordica charantia Linn. var. abbreviata Ser.) in Taiwan. LWT-Food Science and Technology 41(2), 323-330. https://doi.org/10.1016/j.lwt.2007.03.003 